\title{
Nogueira-pecã em sistema agroflorestal
}

\author{
Pecan tree in agroforestry system \\ Pecan en sistema agroforestal
}

Recebido: 30/04/2021 | Revisado: 09/05/2021 | Aceito: 17/05/2021 | Publicado: 04/06/2021

Maurício Gonçalves Bilharva

ORCID: https://orcid.org/0000-0002-1494-3742

Universidade Federal de Pelotas, Brasil

E-mail: mauriciobilharva@gmail.com

Rafaela Schmidt de Souza

ORCID: https://orcid.org/0000-0001-7009-3191 Universidade Federal de Pelotas, Brasil E-mail:souzarafaela15@yahoo.com.br

Rudinei De Marco

ORCID: https://orcid.org/0000-0003-2648-0279 Universidade Federal de Pelotas, Brasil E-mail:rudineidemarco@hotmail.com

Priscila da Silva Lúcio

ORCID: https://orcid.org/0000-0002-6692-6346 Universidade Federal de Pelotas, Brasil E-mail:priscilasilluc@gmail.com

Carlos Roberto Martins

ORCID: https://orcid.org/0000-0001-8833-1629 Embrapa Clima Temperado, Brasil E-mail: carlos.r.martins@embrapa.com

Joel Henrique Cardoso

ORCID: https://orcid.org/0000-0002-1038-260X Embrapa Clima Temperado, Brasil

E-mail: joel.cardoso@embrapa.br Marcelo Barbosa Malgarim

ORCID: https://orcid.org/0000-0002-3584-5228 Universidade Federal de Pelotas, Brasil

E-mail:malgarim@ufpel.edu.br

\begin{abstract}
Resumo
Os sistemas agroflorestais biodiversos são uma estratégia de manejo do solo que busca promover interações benéficas entre componentes bióticos e abióticos. A nogueira-pecã é uma espécie arbórea de ciclo longo e de grande porte, que influenciará de maneira decisiva os sistemas que ela integra. O objetivo deste trabalho é estabelecer padrões de comportamento das cultivares de nogueira-pecã dentro do sistema agroflorestal. Neste experimento realizado entre 2015 e 2017, a cultivar foi o fator de variação avaliado, sendo considerados quatro tratamentos: 'Barton', 'Cape Fear', 'Desirable' e 'Shawnee'. As variáveis analisadas foram: altura e diâmetro das plantas; número de gemas por ramo; número de ramos; diâmetro e comprimento de ramo e números de folhas por ramo; área foliar; número de folíolos, peso fresco e seco; número de racimos e flores; inflorescências e ataque de formiga. Com relação ao comportamento reprodutivo, a cultivar Barton apresentou uma dicogamia do tipo protândrica, 'Cape Fear' oscilou o comportamento, demonstrando-se protogínica na primeira safra e protândrica na seguinte. 'Barton' e 'Cape Fear' demonstraram melhor desempenho reprodutivo do que 'Desirable' e 'Shawnee' em sistemas agroflorestais, porém, requer-se estudos que incluam a fase reprodutiva e considere outras cultivares.
\end{abstract}

Palavras-chave: Cultivares; Desenvolvimento vegetativo; Dicogamia; Protândria; Protogenia.

\begin{abstract}
The biodiverse agroforestry systems are a soil management strategy that seeks to promote beneficial interactions between biotic and abiotic components. Pecan is a long-lived and large-sized tree species that will decisively influence the systems it integrates. The objective of this work is to establish patterns of behavior of pecan cultivars within the agroforestry system. The experiment was carried out between 2015 and 2017, the cultivar was the factor of variation evaluated, considering four treatments: 'Barton', 'Cape Fear', 'Desirable' and 'Shawnee'. The variables analyzed were: plant height and diameter; number of buds per branch; number of branches; branch diameter and length; number of leaves per branch and number of branches at the end of the cycle; leaf area; number of leaflets, fresh and dry weight; number of racemes and flowers; inflorescences and ant attack and. Regarding reproductive behavior , the cultivar Barton showed protandric type dicogamy, 'Cape Fear' oscillated the behavior, showing itself to be protogynic in the first harvest and protandrous in the following. 'Barton' and 'Cape Fear' demonstrated better reproductive performance than
\end{abstract}


'Desirable' and 'Shawnee' in agroforestry systems, however, studies that include the reproductive phase and consider other cultivars are required.

Keywords: Cultivars; Vegetative development; Dichogamy; Protandry; Protogeny.

\section{Resumen}

Los sistemas agroforestales biodiversos son una estrategia de manejo del suelo que busca promover interacciones beneficiosas entre componentes bióticos y abióticos. Pecan es una especie arbórea longeva y de gran porte que influye decisivamente en los sistemas integrados por ella. El objetivo de este trabajo es establecer patrones de comportamiento de cultivares de nuez pecan dentro de un sistema agroforestal. El experimento fue llevado a cabo de 2015 hasta 2017 y el factor de variación evaluado fue cultivar, donde se observó cuatro tratamientos: 'Barton', 'Cape Fear', 'Desirable' y 'Shawnee'. Las variables analizadas fueron: altura y diámetro de la planta; número de yemas por rama; número de ramas; diámetro y longitud de la rama y número de hojas por rama; área foliar; número de folíolos, peso fresco y seco; número de racimos y flores; inflorescencias y ataque de hormigas. En cuanto al comportamiento reproductivo, al variedad Barton mostró una dicogamia de tipo protándrica, el 'Cape Fear', osciló el comportamiento, mostrándose protogénica en la primera cosecha y protándrica en la siguiente. 'Barton' y 'Cape Fear' demostraron un mejor desempeño reproductivo que 'Desirable' y 'Shawnee' en sistemas agroforestales, sin embargo, se requiere estudios que incluyan la fase reproductiva y consideren otras variedades de pecan.

Palabras clave: Variedades de pecan; Desarrollo vegetativo; Dicogamia; Protandria; Protogenia.

\section{Introdução}

A produção mundial de alimentos está fortemente alicerçada aos sistemas de produção convencionais, que se valem de pacotes tecnológicos centrados em insumos químicos de síntese, maquinários e genética dependentes de fontes de energia fósseis (Carvalho, et al., 2004).

A produção de frutas no sistema convencional tem por característica os pomares com diversidade biológica minorada (Dulley, 2003). Uma das consequências da baixa diversidade de espécies vegetais é a propensão aos desequilíbrios populacionais de espécies pragas, que encontram ambientes simplificados ofertando alimentos e abrigo em abundância para espécies oportunistas. Estas crescem exponencialmente sem a presença de predadores ou outros organismos, substâncias ou processos promotores do equilíbrio. Desta forma, o sistema exige que o homem intervenha constantemente no funcionamento do sistema, principalmente por meio da aplicação de produtos químicos de síntese que são utilizados para nutrir as plantas e controlar a ação de organismos que causam prejuízos as colheitas, como vírus, fungos, bactérias e insetos (Chaboussou, 2006).

Fazendo contraponto aos sistemas de cultivo convencional estão as estratégias de cultivo que buscam o equilíbrio ecológico entre os organismos, de modo que o ser humano deixa de poluir o ambiente com produtos químicos de síntese utilizados como biocidas e passa a manejar o ambiente para que as interações bióticas e abióticas sejam mais equilibradas. Os sistemas agroflorestais (SAF's) são estratégias de cultivo que buscam aproveitar as interações ecológicas positivas dos diferentes organismos que se relacionam em determinado espaço e tempo, cabendo ao ser humano criar as condições para que as sinergias sejam positivas, gerem boas colheitas e melhorem a qualidade do ambiente. Outra forma utilizada para melhorar os atributos químicos e a qualidade do solo, são os sistemas silvipastoril que em estudos demonstram serem promissores trazendo muitos benefícios (Vasconcelos, et al., 2015; Battisti, et al., 2018).

O sistema agroflorestal tem por característica inserir práticas de uso e manejo agrícola com a existência do componente arbóreo, da diversidade de espécies e de grande produção de biomassa, em que o componente vegetal busca maximizar a oferta de luz e nutrientes (Ewert, et al., 2016).

A elaboração do sistema agroflorestal passa pelas escolhas das espécies (Righi \& Bernardes, 2015). Por definição, considera-se sistemas agroflorestal um determinado cultivo que consorcie pelo menos duas espécies, sendo que uma delas necessita obrigatoriamente apresentar porte arbóreo na fase adulta (Nair, 1993). Porém, quanto maior o número de espécies, mais elevada será a complexidade das interações, algo que se bem conduzido tende a garantir maior estabilidade para o sistema.

No Brasil, o cultivo da nogueira-pecã tem sido frequentemente conduzido em plantios monoculturais, havendo algumas experiências exitosas em sistemas silvipastoris. Em menor escala, também pode-se observar o cultivo na entrelinha 
com espécies produtoras de grãos (Fronza, et al., 2013). Há estudos preliminares sobre a utilização de espécies de cobertura juntamente à nogueira-pecã, como é o caso relatado por Wells (2011), que cultivou trevo (Trifolium incarnatum L.) constatando a melhoria atributos do solo.

Os estudos no Brasil, com a inclusão da nogueira-pecã nos sistemas agroflorestais ainda são recentes. Já nos Estados Unidos há vários estudos sobre o cultivo de nogueira-pecã, entre estes o que relata está espécie intercalada com pêssego (Smith, et al., 1989).

O cultivo único da nogueira-pecã exige o controle de espécies herbáceas, já no sistema agroflorestal ocupa-se os espaços com a introdução de espécies de interesse que cumprem funções de adubação, produção de alimentos, madeiras ou outros bens e serviços ecossistêmicos como proteção contra a incidência direta do vento, chuva ou raios solares, assim como a produção de néctar, resinas ou produtos fitoterápicos (Machado Filho \& Silva, 2012).

Nos Estados Unidos, principal produtor de noz-pecã, exigem grandes áreas de cultivo, assim como há locais com populações nativas, onde ocorre o extrativismo. Estas populações coexistem e interagem com outras espécies, o que orienta a composição dos consórcios vegetais. Reid e Hunt (2000) relatam que no norte dos Estados Unidos há uma grande região produtora com aproximadamente 5\% da produção total do país. A maior parte dos frutos desta áreas provém de áreas nativas.

A existência de ferramentas para o monitoramento da nogueira-pecã são imprescindíveis para intuir o comportamento das cultivares, principalmente para saber quais cultivares mais adequadas para o sistema agroflorestal. Assim, objetivo desta pesquisa foi melhor entender a aptidão de diversas cultivares de nogueira-pecã para a utilização em sistemas agroflorestais.

\section{Material e métodos}

O experimento foi realizado na Embrapa Clima Temperado, Estação Experimental Cascata, localizada no município

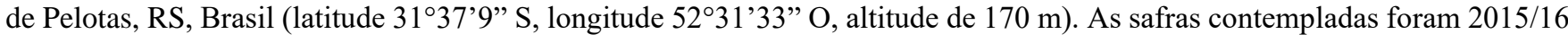
e 2016/17. O clima da região é subtropical úmido - Cfa conforme Köeppen. Os dados meteorológicos foram extraídos da unidade Embrapa Estação Cascata já que o experimento fica a aproximadamente 100 m da estação meteorológica (Tabela 1).

Tabela 1. Dados de horas de frio acumulada, precipitação e temperatura média. Pelotas, RS, Brasil, 2017.

\begin{tabular}{cccc}
\hline Safra & Horas de frio acumulada* & Precipitação $(\mathrm{mm})$ & Temperatura média $\left({ }^{\circ} \mathrm{C}\right)$ \\
\hline $2015 / 2016$ & 219 & 1905,1 & 20,3 \\
$2016 / 2017$ & 348 & 939,2 & 20,4 \\
\hline
\end{tabular}

* Temperatura $\leq 7,2^{\circ} \mathrm{C}$. Fonte: Autores.

O delineamento experimental adotado foi em blocos ao acaso compostos por quatro blocos, sendo que cada unidade experimental continha uma planta. As cultivares utilizadas foram Barton, Cape Fear, Desirable e Shawnee. O experimento se apresentou em esquema fatorial (cultivares e safras).

O solo foi identificado como Argissolo, logo, apresenta como característica horizonte B textural de argila com atividade baixa ou alta conjugada com saturação por bases baixa (Santos, et al., 2018).

O sistema agroflorestal multiestrato continha 17 espécies arbóreas perenes, das quais seis eram frutíferas. As nogueiras-pecã foram implantadas em 2013. O espaçamento utilizado foi o 10 x $10 \mathrm{~m}$.

As espécies arbóreas perenes são: Açoita-cavalo (Luehea divaricata); Canafístula (Peltophorum dubium); Caqui (Diospyros kaki); Cedro (Cedrus spp.); Goiaba (Psidium guajava); Guajuvira (Patagoluna americana); Ingá (Inga spp.); Laranjeira (Citrus X sinensis); Louro (Laurus nobilis); Pêssego-do-mato (Hexachlamys edulis); Tangerina (Citrus reticulata); 
Tarumã (Citharexylum montevidense); Timbaúva (Enterolobium contortisiliquum); Trema (Trema micrantha); Uva-do-Japão (Hovenia dulcis).

As variáveis coletadas foram: as características fenológicas, número de gemas por ramo, número de ramos, número de folhas por ramos, ataque de formiga, altura e diâmetro de plantas e ramos, número de racimos e flores por racimos. Além dessas variáveis, foram avaliadas a área foliar, a descrição do número de folíolos e o peso verde e seco do material coletado.

As características fenológicas compreendem a fase reprodutiva. Os estádios fenológicos utilizados provêm de Reyes \& Lavín (2014). No que se refere aos estádios da fase reprodutiva, foi considerado os seguintes estádios fenológicos: surgimento da inflorescência; floração plena; queda das pétalas; amentos de até $5 \mathrm{~cm}$; amentos com mais de $5 \mathrm{~cm}$; alongamento do amento; amento seco; queda dos amentos; fruto em desenvolvimento.

Foi avaliado o número de ramos no início da safra (em setembro), os quais foram quantificados no período em que as nogueiras-pecã se direcionam para a dormência (em abril). O número de gemas por ramos foi analisado em setembro, enquanto o número de folhas por ramo foi avaliado apenas em abril. A incidência de formiga foi avaliada juntamente aos estádios fenológicos quando também foi realizada a contagem do número de racimos e flores. Para a avaliação desses ataques, foi considerada o tipo de dano causado pela formiga e a forma como se expressa na planta. Para efeito de análise foi considerado a planta ser atacada ou não pela formiga.

A altura foi mensurada a partir da base da planta até o ápice do tronco com o auxílio de uma trena com graduação em centímetros. Quanto ao diâmetro do tronco, foi utilizada como referência a altura de $15 \mathrm{~cm}$ do solo para as medições. No período em que se avaliava altura e diâmetro da planta, também era mensurada a altura e diâmetro do ramo. Para tanto, a altura do ramo foi considerada a partir da base que saía do tronco principal até o ápice do ramo, enquanto que para o diâmetro a avaliação se dava na base do ramo próximo ao tronco principal. O equipamento utilizado para essas mensurações foi um paquímetro digital com medida em milímetros, que, posteriormente, foi convertido em centímetros.

A avaliação da área foliar foi realizada pelo método destrutivo, ou seja, foram coletadas, em fevereiro de 2016, cinco folhas por plantas, as quais foram levadas para o laboratório, a fim de serem avaliadas pelo aparelho medidor de área foliar, LICOR 3100, o qual é expresso em cm². Após a mensuração, os folíolos foram contabilizados e pesados em balança de precisão de $0,01 \mathrm{~g}$, apresentando peso fresco. Em seguida, foram encaminhados para a estufa de secagem, com temperatura de $65^{\circ} \mathrm{C}$. $\mathrm{O}$ material foi retirado da estufa somente quando o peso se fez constante.

Os dados das variáveis analisadas foram submetidos à análise de variância (ANOVA). No caso de significância, foi realizado o teste de comparação de média (Tukey a 5\%). Foram testadas as regressões lineares e quadráticas para as variáveis de altura e diâmetro de planta.

\section{Resultados e Discussão}

O acompanhamento da altura e diâmetro da planta avaliou o crescimento da nogueira-pecã, variáveis importantes para que se conheça o padrão de crescimento dentro do Sistema Agroflorestal (SAF), principalmente-se forem consideradas as espécies arbóreas pois estas determinam o efeito sinérgico ou antagônico das relações de crescimento e desenvolvimento. As cultivares Barton, Desirable e Shawnee tiveram um comportamento quadrático (Figura 1A), enquanto a cultivar Cape Fear demonstrou um comportamento linear crescente. As três primeiras cultivares, em agosto de 2014, tiveram um decréscimo no crescimento, primordialmente, porque houve uma poda do ápice das plantas e devido ao fato da primeira medição ter ocorrido no verão e a segunda avaliação no inverno, após o período de dormência, ou seja, no período hibernal. Logo, há uma inanição do crescimento e desenvolvimento da nogueira-pecã.

Nas regressões das cultivares referentes ao diâmetro, todos os dados apresentaram comportamento quadrático (Figura 1B), a equidistância entre as duas primeiras avaliações decresceram, porém, os valores oscilaram entre 0,38 a 2,37 mm. 'Barton' 
e 'Cape Fear' apresentaram, tanto na altura quanto no diâmetro, índices maiores que a 'Desirable' e a 'Shawnee', demonstrando, de certa forma, uma maior adaptabilidade das duas primeiras cultivares no sistema agroflorestal.

Figura 1. Regressão da altura - (A) e diâmetro - (B) das cultivares de nogueira-pecã no Sistema Agroflorestal. Pelotas-RS, 2017.
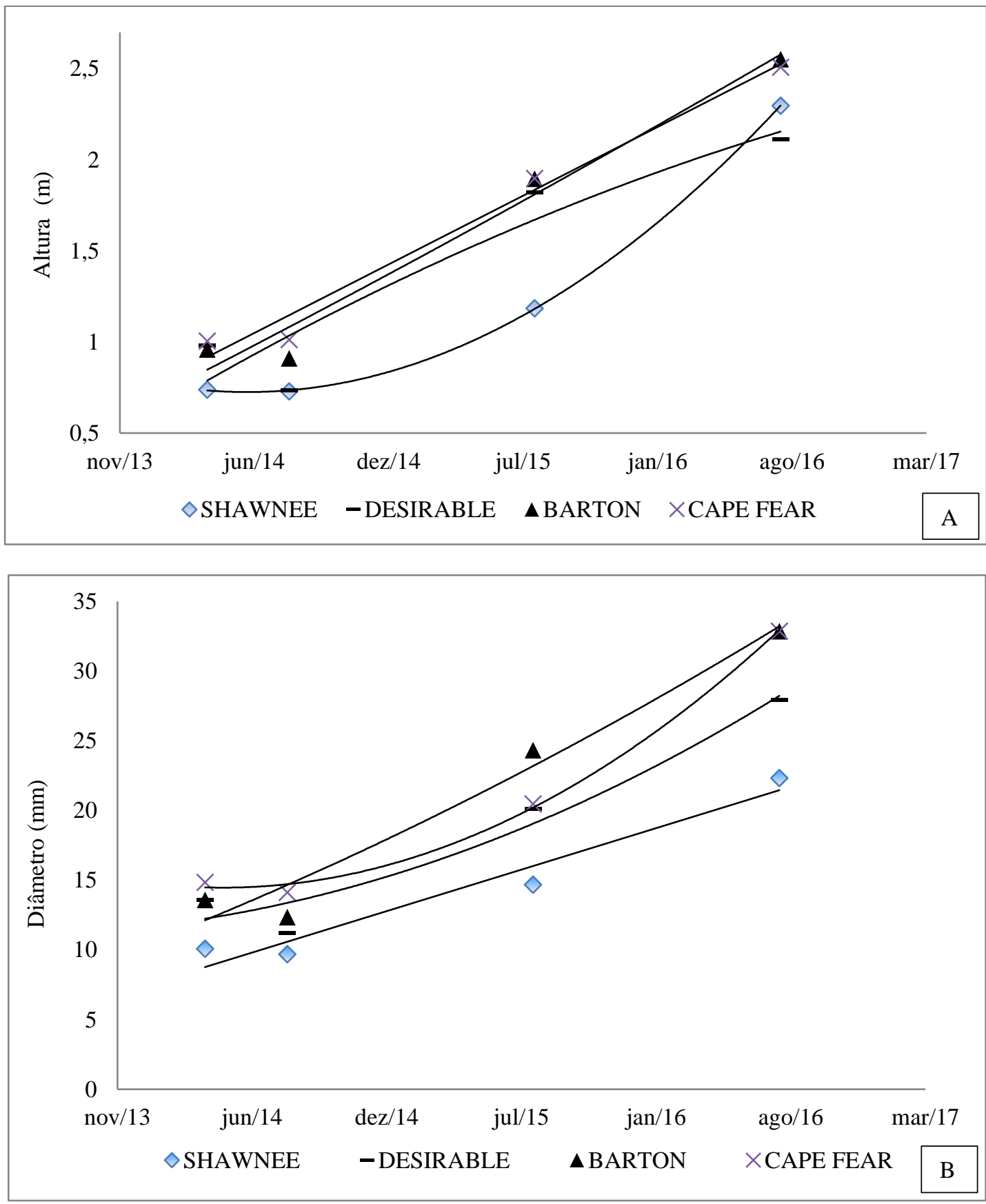

Fonte: Autores.

Boscardin, et al. (2017) avaliaram a implantação de nogueira-pecã em sistema convencional em diferentes preparos de solo e coveamento e obtiveram um incremento de diâmetro e altura na ordem de 62,8 e 43,8\%, respectivamente. Em Sistema Agroflorestal a média geral concernente ao diâmetro e a altura obtiveram os valores de 67,8 e 107\%, respectivamente. Desta forma, demonstra-se que, dentro do SAF, o incremento em altura foi maior, provavelmente em função da relação entre as 
plantas e o espaçamento entre elas dentro do sistema que fica próximo de um metro. Isto pode fazer com que a planta tenha uma maior propensão ao crescimento vertical. Ressalta-se para efeito de comparação que foram considerados os dados avaliados em agosto de 2014 e 2015.

A determinação do número de gemas e ramos prospecta, em partes, a produção da espécie. A maior quantidade de ramos conciliada à boa disposição do dossel potencializa a produção de frutos (Andales, et al., 2006). Quanto ao número de gemas por ramo, diâmetro e comprimento de ramo (Tabela 2), não houve diferença. Ao que se refere ao número de ramos, em que houve diferença estatística, a cultivar que demonstrou maior quantidade de ramificações foi a 'Barton' (19,33), seguida da 'Cape Fear' (12,67). Por fim, as cultivares que apresentaram índices dentro do mesmo nível foram: 'Desirable' (12) e 'Shawnee' $(11,33)$. O maior número de ramos na cultivar Barton possibilitou a antecipação na entrada do período produtivo, produzindo seus primeiros frutos já na safra 2016/17. Em relação ao comprimento do ramo, o experimento demonstrou, de modo geral, um intervalo de, aproximadamente, 93 a $119 \mathrm{~cm}$, o qual é de 1,8 a 2,3 vezes maior que o mencionado por Arreola-Avila, et al. (2010).

Tabela 2. Número de gemas por ramo, número de ramos, diâmetro do ramo e comprimento do ramo das cultivares de nogueirapecã no Sistema Agroflorestal. Pelotas, RS, Brasil, 2017.

\begin{tabular}{ccccc}
\hline Cultivar & $\begin{array}{c}\text { Número de } \\
\text { gemas por ramo }\end{array}$ & Número de ramos* & Diâmetro do ramo (mm) & Comprimento do ramo (cm) \\
\hline Barton & $16,20^{\text {ns }}$ & $19,33 \mathrm{~A}$ & $14,6^{\text {ns }}$ & $119,50^{\text {ns }}$ \\
Cape Fear & 12,60 & $12,67 \mathrm{AB}$ & 14,3 & 112,19 \\
Desirable & 14,27 & $12,00 \mathrm{~B}$ & 12,0 & 93,21 \\
Shawnee & 16,00 & $11,33 \mathrm{~B}$ & 11,6 & 107,07 \\
\hline CV $(\%)$ & 10,52 & 17,91 & 11,47 & 14,99 \\
\hline
\end{tabular}

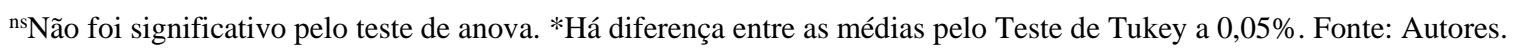

Em relação ao número de folhas por ramo e ao número de ramos no final do ciclo, não observou-se diferença significativa.

A medida da área foliar é primordial para que se tenha os parâmetros e o padrão de comportamento das cultivares dentro do sistema agroflorestal. Nas avaliações de área foliar, o número de folíolo médio e o peso fresco não apresentaram diferença significativa (Tabela 3). Porém, no peso seco houve diferença significativa. A cultivar Desirable demonstrou maior peso (2,58 g), seguido por Cape Fear e Shawnee (ambos com 2,05 g), por fim, o menor valor foi da Barton, com 1,67 g.

A área foliar relatada dentro do SAF está próxima ao valor encontrado por Smith, et al. (2001), que teve como padrão valores entre 887 e $1247 \mathrm{~cm}^{2}$ de área total. O número de folíolos, por sua vez, é encontrado dentro do intervalo caracterizado pela cultura (Fronza, et al., 2018). 
Tabela 3. Área foliar, número de folíolo médio, peso fresco e seco das cultivares de nogueira-pecã no Sistema Agroflorestal. Pelotas, RS, Brasil, 2017.

\begin{tabular}{ccccc}
\hline Cultivar & Área foliar $\left(\mathrm{cm}^{2}\right)$ & $\begin{array}{c}\text { Número de folíolo } \\
\text { médio }\end{array}$ & $\begin{array}{c}\text { Peso fresco } \\
(\mathrm{g})\end{array}$ & $\begin{array}{c}\text { Peso seco } \\
(\mathrm{g}) *\end{array}$ \\
\hline Barton & $836,79^{\mathrm{ns}}$ & $10,80^{\mathrm{ns}}$ & $3,69^{\mathrm{ns}}$ & $1,67 \mathrm{~B}$ \\
Cape Fear & 1088,23 & 10,98 & 4,60 & $2,05 \mathrm{AB}$ \\
Desirable & 1211,44 & 12,47 & 5,73 & $2,58 \mathrm{~A}$ \\
Shawnee & 940,02 & 11,07 & 4,33 & $2,05 \mathrm{AB}$ \\
\hline cv $(\%)$ & 14,75 & 6,91 & 16,22 & 26,14 \\
\hline
\end{tabular}

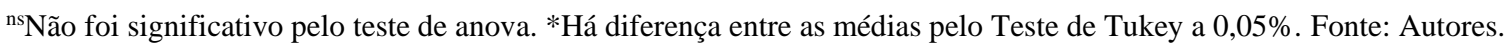

$\mathrm{Na}$ fase de implantação do pomar, é importante acompanhar o desenvolvimento da nogueira-pecã, sendo que um dos fenômenos importantes é o período florífero. Sendo assim, tem-se a possibilidade de encontrar cultivares que apresentem potencial de precocidade no período de disponibilidade de flores (estaminadas e pistiladas). Deste modo (Tabela 4), a flor feminina estava presente apenas nas cultivares Barton e Cape Fear. Na primeira safra, ambas apresentaram a média de 2 racimos, enquanto, na segunda safra, apenas a 'Cape Fear' aumentou para 4,5 racimos em média. O acréscimo de racemos entre safras foi significativo e provavelmente, está relacionado com o maior desenvolvimento da planta e a maior adaptabilidade da cultivar dentro do sistema agroflorestal. Referente ao número de flores, na primeira safra foram encontradas 4 e 8 flores na 'Barton' e na 'Cape Fear', respectivamente. Na segunda safra, a 'Barton' incrementou em 50\%, passando a apresentar uma média de 6 flores. $\mathrm{Na}$ 'Cape Fear' houve um decréscimo, o que expôs em média 5,8 flores. A única cultivar que denotou produção foi a Barton, com dois frutos.

Tabela 4. Número de cachos e flores das cultivares Barton e Cape Fear no Sistema Agroflorestal, Pelotas-RS, 2017.

\begin{tabular}{ccccc}
\hline & \multicolumn{2}{c}{ Racimos } & 2016 & Flores \\
\cline { 2 - 6 } & 2016 & 2017 & 4 & 6 \\
\hline Barton & 2 & 2 & 8 & 5,8 \\
Cape Fear & 2 & 4,5 & 8 & \\
\hline
\end{tabular}

Fonte: Autores.

Um parâmetro importante na implantação da nogueira-pecã é a incidência de ataque de insetos, principalmente da formiga cortadeira. Na Tabela 5 apresenta o quanto de danos que ocorreu em cada cultivar devido ao ataque e/ou presença desses insetos. Na primeira safra, o dano da formiga foi presente em 16,6\% das plantas da cultivar Barton e para Cape Fear de 20\%. As demais cultivares não apresentaram danos. Porém, na segunda safra, apenas a 'Barton' não sofreu danos. Na segunda safra, na 'Cape Fear' houve um incremento de 5\% em relação à safra passada, chegando a 25\%. Valor coincidente de $25 \%$ foi observado para a cultivar 'Shawnee'. 
Tabela 5. Incidência em porcentagem do dano de formigas nas cultivares de nogueira-pecã no Sistema Agroflorestal. Pelotas, RS, Brasil, 2017.

\begin{tabular}{cccc}
\hline & \multicolumn{3}{c}{ Dano por formiga } \\
\cline { 3 - 4 } Cultivar & 2016 & 2017 \\
\hline Barton & 16,6 & - \\
Cape fear & 20 & 25 \\
Desirable & - & 20 \\
Shawnee & - & 25 \\
\hline
\end{tabular}

Fonte: Autores.

A sincronização de floração na nogueira-pecã é crucial para que se obtenha uma boa produção de frutos. Desta forma, na Figura 2 consta o desenvolvimento florífero masculino e feminino desta espécie.

Figura 2. Desenvolvimento da floração masculina e feminina das cultivares de nogueira-pecã no Sistema Agroflorestal, PelotasRS, 2017.

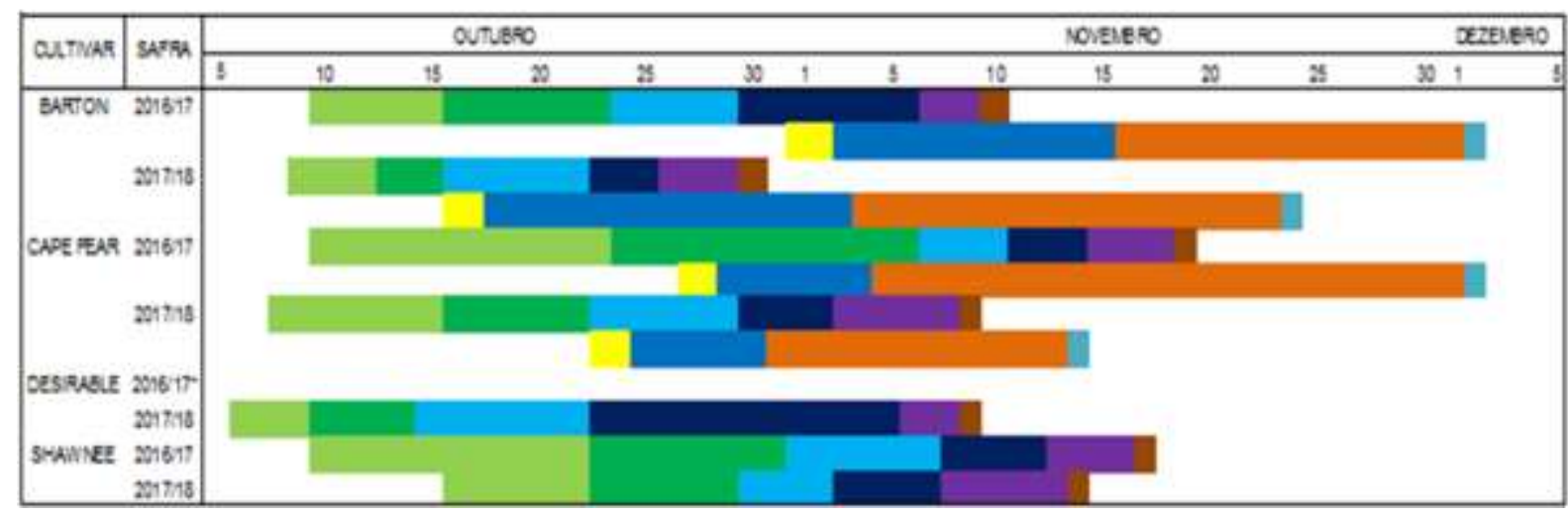

Fonte: Autores.

A cultivar Barton quanto ao desenvolvimento da flor masculina, apresentou amento de até $5 \mathrm{~cm}$ entre as datas de 10 a 15 de outubro nas duas safras. Este estádio de amento até $5 \mathrm{~cm}$ foi encontrado na safra 2015/16 na da cultivar Cape Fear entre 10 a 22 de outubro, ao passo que, na safra 2016/17 os amentos atingiram este estádio entre os dias 8 a 16 de outubro. Na primeira safra da 'Desirable', não foram encontradas nas plantas a formação de floração masculina e feminina. Na segunda safra, a formação do amento de até $5 \mathrm{~cm}$ se deu entre os dias 5 e 10 de outubro. A 'Shawnee' apresentou esse estádio na primeira safra, entre 10 e 23 de outubro, e a segunda safra ficou entre 15 e 23 de outubro. Desta forma, a cultivar que demonstrou a formação mais antecipada foi a 'Desirable', porém, não ficou equidistante das demais cultivares. As cultivares nesse estádio ficaram concentradas praticamente no meio do mês de outubro.

No estádio de amento com mais de $5 \mathrm{~cm}$, a cultivar Barton, na primeira safra, ficou situada entre os dias 15 e 23 de outubro e, na segunda safra, entre os dias 13 e 15 de outubro. No caso da cultivar Cape Fear, na primeira safra, o estádio de amento com mais de $5 \mathrm{~cm}$ se estendeu de 24 de outubro a 6 de novembro. Em contrapartida, na segunda safra, o período compreendeu de 15 a 23 de outubro. Deste modo, para ambas as cultivares, o estádio foi antecipado quando comparasse as safras. Ao que concerne à 'Desirable', na segunda safra, o estádio citado se concentrou entre os dias 10 e 15 de outubro, corroborando sua precocidade perante as demais cultivares. A 'Shawnee' expôs amentos com mais de $5 \mathrm{~cm}$ na primeira safra, entre 23 e 31 de outubro, e na safra seguinte reduziu, ficando entre 23 e 29 de outubro. 
No estádio de alongamento do amento, a cultivar Barton denotou, na primeira safra, um posicionamento entre as datas do dia 24 e 29 de outubro, na safra subsequente, foi de 16 a 22 de outubro. Na cultivar Cape Fear, a primeira safra esboça um período curto de 6 a 10 de novembro e referência a safra posterior no período de 24 a 29 de outubro. No caso da Desirable, as datas compreenderam entre 15 e 23 de outubro. Para a 'Shawnee', na primeira safra, o período se deu entre 2 e 7 de novembro, na segunda safra, entre 31 de outubro e 3 de novembro.

No estádio de plena emissão de pólen, a 'Barton', na safra 2016/17, ficou situada entre 30 de outubro e 6 de novembro, e na safra seguinte mostrou-se entre 23 e 25 de outubro. Para a cultivar Cape Fear, na primeira safra o período estabelecido para esse estádio foi de 11 a 14 de novembro. Para a segunda safra o período compreendeu entre 23 e 29 de outubro. A cultivar Desirable, na safra 2017/18 teve o período de emissão de pólen entre 23 de outubro e 6 de novembro. Shawnee na primeira safra, teve a emissão do pólen situada entre as datas de 7 a 11 de novembro. Na segunda safra ficou no período de 3 e 7 de novembro.

Após a floração masculina cumprir a sua funcionalidade, o estádio presente é de amento seco. Nesse caso, a 'Barton' insere o estádio presente nas datas de 7 a 9 de novembro e a segunda safra, a qual foi antecipada entre 26 e 29 de outubro. Já a 'Cape Fear' na safra 2016/17 situou-se entre 15 e 19 de novembro, enquanto que a segunda safra expôs o amento seco nas datas de 3 a 9 de novembro. A 'Desirable' na safra 2017/18 teve o amento seco entre 7 e 9 de novembro. A 'Shawnee' apresentou esse estádio na primeira safra entre 13 e 17 de novembro. Na safra posterior os amentos estavam secos entre 8 e 13 de novembro.

$\mathrm{Na}$ floração feminina, tem-se como princípio o estádio da aparição do botão floral. É importante ressaltar que as cultivares avaliadas Barton e Cape Fear tiveram a condição de receptividade do estigma. Na 'Barton' a aparição ocorreu nos dias 1 e 2 de novembro na primeira safra. A safra seguinte foi mais antecipada ocorrendo entre as datas de 16 e 17 de outubro. $\mathrm{Na}$ 'Cape Fear' a aparição ocorreu nos dias 27 e 28 de outubro, na safra 2016/17. Já na safra 2017/18 as datas foram 23 e 24 de outubro.

O estádio mais importante da nogueira-pecã é a condição de receptividade do estigma (plena floração). Nesse caso, a 'Barton' demonstrou um período de 3 a 15 de novembro, ao passo que na safra 2017/18 esteve presente entre 18 de outubro e 3 de novembro. Na Cape Fear, o estádio na safra 2016/17 foi de 31 de outubro a 4 de novembro. Para safra seguinte, o estádio de plena floração esteve de 25 a 30 de outubro.

Ao que concerne ao estádio posterior, em que ocorre a queda das pétalas, a cultivar Barton na safra 2016/17 apresentou o período de 16 de novembro a 1 de dezembro, na safra de 2017/18, ficou entre 4 e 23 de novembro. Para a cultivar Cape Fear, o período para a primeira safra foi de 4 de novembro a 1 de dezembro, ao passo que a safra posterior demonstrou as datas de 31 de outubro a 13 de novembro.

$\mathrm{Na}$ fase final da floração feminina passa-se para o processo de formação do fruto dentro estágio reprodutivo. Desta forma a formação do fruto na 'Barton' começa no dia de 2 dezembro, primeira safra, e 24 de novembro, segunda safra. Para a cultivar Cape Fear, as datas da safra 2016/17 e 2017/18 foram, respectivamente, 2 de dezembro e 14 de novembro. Ademais, das cultivares que desenvolveram fruto, apenas a 'Barton', na segunda safra, conseguiu a formação do fruto, a outra cultivar apresentou frutos com desenvolvimento parcial, os quais acabaram abortados.

No aspecto da dicogamia, fenômeno recorrente na nogueira-pecã, a Barton demonstrou um comportamento com dicogamia protândrica, enquanto a cultivar Cape Fear teve por característica uma oscilação entre as safras. Na primeira ocorreu com dicogamia protogínica e na safra posterior, a protândrica. As demais cultivares não apresentaram dicogamia, pois não houve o aparecimento aparente da flor no estigma. Os dados observados neste experimento divergem dos apresentados na revisão elaborada por Fronza, et al. (2018) que definem a cultivar Barton como protogínica. Levando-se em consideração apenas a primeira safra, a Cape Fear apresenta o mesmo desempenho quanto à dicogamia. Ao que compete a Cape Fear, a 
cultivar foi igual se considerado apenas a primeira safra. Worley, et al. (1992) encontraram para a Barton condição protogínica, enquanto para a Cape Fear um comportamento protândrico.

Portanto, as cultivares Barton e Cape Fear apresentam-se a uma condição de precocidade e potencial para produção em relação a Desirable e a Shawnee. As últimas ainda não permitem tal definição em função de não apresentarem uma reprodução florífera completa. Por mais que Barton e Cape Fear tenham apresentado melhor desempenho que Desirable e Shawnee, adverte-se que estes dados precisam ser avaliados por um período maior contrastando-se um número maior de cultivares em sistemas agroflorestais.

\section{Conclusão}

As cultivares de nogueira-pecã Barton e Cape Fear foram mais precoces que Desirable e Shawnee em condições de cultivo agroflorestal, pois ambas apresentaram reprodução florífera completa e formação de frutos.

A indicação destas cultivares para compor sistemas agroflorestais com nogueira-pecã precisam ser validados em outras safras. Também faz-se necessário a repetição deste estudo com outras cultivares.

\section{Referências}

Andales, A., Wang, J., Sammis, T. W., Mexal, J. G., Simmons, L. J., Miller, D. R. \& Gutschick, V. (2006). A modelo of pecan tree growth for the management of pruning and irrigation. Agricultural Water Management, 84 (1-2), 77-88.

https://www.academia.edu/10413237/A_model_of_pecan_tree_growth_for_the_management_of_pruning_and_irrigation

Arreola-Avila, J. G., Murrieta, A. L. \& Rosa, A. B. (2010). Inducción de crecimiento lateral em nogal pecanero (Carya illinoensis K. Koch) mediante despuente de brotes em primavera. Revista Chapingo, 16 (1), 31-36. http://www.scielo.org.mx/pdf/rcsh/v16n1/v16n1a5.pdf

Battisti, L. F. Z., Schmitt Filho, A. L., Loss, A., \& Sinisgalli, P. A. (2018). Soil chemical attributes in a high biodiversity silvopastoral system. Acta Agronômica, 67 (4), 486-493.http://www.scielo.org.co/scielo.php?script=sci_abstract\&pid=S0120-28122018000400486

Boscardin, J., Costa, E. C., Paulus, E., Machado, D. N., Pedron, L. \& Silva, P. G. (2017). Crescimento de nogueira-pecã sob diferentes preparos do solo e coveamentos: coleópteros como bioindicadores. Pesquisa Florestal Brasileira, 37 (92), 587-596.

https://pfb.cnpf.embrapa.br/pfb/index.php/pfb/article/view/1496/614

Carvalho, R., Goedert, W. J. \& Armando, M. S. (2004). Atributos físicos da qualidade do solo sob sistema agroflorestal. Pesquisa Agropecuária Brasileira, 39 (11), 1153-1155. https://www.scielo.br/pdf/pab/v39n11/22589.pdf

Chaboussou, Francis (2006). Plantas Doentes Pelo Uso de Agrotóxicos. Ed. Expressão Popular. 320p.

Dulley, R. D. (2003). Agricultura Orgânica, Biodinâmica, Natural, Agroecológica ou Ecológica. Informações Econômicas Agrícola, 33 (10), 9699.http://www.iea.sp.gov.br/OUT/publicacoes/pdf/seto3-1003.pdf

Ewert, M., Venturieri, G. A., Steenbock, W. \& Seoane, C. E. S. (2016). Sistemas agroflorestais multiestrata e a legislação ambiental brasileira: desafios e soluções. Desenvolvimento e Meio Ambiente, 36, 95-114.file:///C:/Users/Usuario/Downloads/39944-177254-1-PB.pdf

Fronza, D., Poletto, T. \& Hamann, J. J. (2013). O cultivo da nogueira-pecã. Santa Maria: Universidade Federal de Santa Maria, Colégio Politécnico, Núcleo de Fruticultura Irrigada.

Fronza, D., Hamann, J. J., Both, V., Anese, R. de O. \& Meyer, E. A. (2018). Pecan cultivation: general aspects. Ciência Rural, 48 (2), 1-9. https://www.scielo.br/scielo.php?script=sci_arttext\&pid=S0103-84782018000200201

Machado Filho, G. C. \& Silva, F. R. da. (2012) . Benefícios sociais, econômicos e ambientais dos sistemas agroflorestais (SAFs) em pequenas propriedades rurais. Inclusão Social, 6 (1), 219-225.

file:///C:/Users/Usuario/Downloads/1704-Texto\%20do\%20artigo-2408-1-10-20160328.pdf

Nair, P. K. R. (1993). An introduction to agroforestry. Dodrecht, The Netherlands: Kluwer Academic Publishers $e$ ICRAF, 51, 246-248. http://apps.worldagroforestry.org/Units/Library/Books/PDFs/32_An_introduction_to_agroforestry.pdf?n=161

Reid, W. \& Hunt, K. L. (2000). Pecan Production in the Northerm United States. HortTechnology, 10 (2), 298 - 301. https://journals.ashs.org/horttech/view/journals/horttech/10/2/article-p298.xml

Reyes, M. R., Lavín A. A. (2014). Frutales de Nuez, Cinco alternativas no tradicionales para el secano interior del Maule. In: Reyes M. R.; Lavín A. A. Pecano (Carya illinoensis Koch.). Chillán. Boletín Inia 301. 138p. file:///C:/Users/Usuario/Downloads/NR40190.pdf

Righi, C. A. \& Bernardes, M. $\quad$ S. $\quad$ (2015). Cadernos da Disciplina Sistemas $\quad$ Agroflorestais. <https://s3.amazonaws.com/academia.edu.documents/37740302/Cadernos_Disciplina_SAFs_2013_Montagem.pdf?responsecontentdispotion=inline\%3B\%20f ilename\%3DCaderno_da_Sistemas_Agroflore.pdf\&X-Amz-Algorithm=AWS4-HMAC-SHA256\&X- 
Research, Society and Development, v. 10, n. 6, e39710615637, 2021

(CC BY 4.0) | ISSN 2525-3409 | DOI: http://dx.doi.org/10.33448/rsd-v10i6.15637

AmzCredential=AKIAIWOWYYGZ2Y53UL3A\%2F20191127\%2Fus-east-1\%Fs3\%2Faws4 request\&X-Amz-Date=20191127T113645Z\&X-Amz-

Expires=3600\&X-Amz-SignedHeaders=host\&X-Amz-Signature=0c694baf1384dd19b3a8ee155d52aad0ddf3357944c73c1e1b92056fc3410e99\#page=7 .

Santos, H. G. Dos., Jacomine, P. K. T., Anjos, L. H. C. Dos, Oliveira, V. A. De., Lumbreras, J. F., Coelho, M. R., Almeida, J. A. De., Araujo Filho, J. C. De., Oliveira, J. B. De \& Cunha, T. J. F. (2018). Sistema Brasileiro de Classificação de Solos. Embrapa, (5a ed.), 356.

https://www.infoteca.cnptia.embrapa.br/handle/doc/1094003

Smith, M. W., Taylor, G. G., Karner, K. \& Couvillon, G. A. (1989). Evaluation of Pecan/Peach Interplanting Systems. Scientia Horticulturae, $40(2), 133-137$. https://www.sciencedirect.com/science/article/abs/pii/0304423889900952

Smith, M.W., Wolf, M. E.; Cheary, B. S. \& Carroll, B. L. (2001). Allelopathy of Bermudagrass, Tall Fescue, Redroot Pigweed, and Cutleaf Evening Primrose on Pecan. HortScience, 36 (6), 1047-1048. file:///C:/Users/Usuario/Downloads/Allelopathy_of_Bermudagrass_Tall_Fescue_Redroot_Pi.pdf

Vasconcelos, M. A. M., Pedroso, A. J. S., Resque, A. G. L., Birani, S. M. \& Kato, O. R. (2015). Crédito e renda como fator de influência no uso da terra na região nordeste do estado do Pará. Cadernos de Agroecologia, 10 (3).

Wells, M. L. (2011). Response of Pecan Orchard Soil Chemical and Biological Quality Indicators to Poultry Litter Application and Clover Cover Crops. HortScience, 46 (2), 306-310. file://C:/Users/Usuario/Downloads/[23279834\%20-\%20HortScience]\%20Response\%20of\%20Pecan\%20Orchard\%20Soil\%20 Chemical\%20and\%20Biological\%20Quality\%20Indicators\%20to\%20Poultry\%20Litter\%20Application\%20and\%20Clover\%20Cover\%20Crops.pdf

Worley, R. E., Dove, S. K., Mullinix JR, B. G. \& Smith, M. (1992). Long-term dichogamy of 80 pecan cultivars. Scientia Horticulturae, 49, $93-101$. https://www.sciencedirect.com/science/article/abs/pii/0304423892901464 